\title{
Eficiência econômica de cultivares de coentro consorciado com rabanete adubado com jitirana mais esterco bovino
}

\section{Economic efficiency of intercropping coriander and radish cultivars fertilized with manure bovine jitirana}

\author{
Bárbara Bruna Maniçoba Pereira $*^{1}$, Paulo César Ferreira Linhares ${ }^{2}$, Jéssyca Duarte de Oliveira ${ }^{3}$; Brenna Rafaella \\ Veríssimo dos Santos ${ }^{4}$; Patrício Borges Maracajá ${ }^{5}$
}

\begin{abstract}
Resumo: Dentre as hortaliças cultivadas em sistema consorciado nas áreas de produção familiar, encontra-se o coentro e o rabanete, espécies de ciclo curto (de 30 a 35 dias para o coentro) e (de 25 a 30 dias para o rabanete). Essas espécies são cultivadas na região de Mossoró/RN em sistema orgânico de produção onde se utiliza esterco bovino como adubo. Assim, um experimento foi conduzido na Fazenda Experimental Rafael Fernandes, Mossoró-RN, no período de agosto a outubro de 2014, com o objetivo de avaliar a eficiência econômica de cultivares de coentro consorciado com rabanete adubado com jitirana mais esterco bovino. O trabalho foi conduzido no delineamento de blocos completos casualizados em esquema fatorial $2 \mathrm{x} 5$, com três repetições. O primeiro fator foi constituído de duas cultivares de coentro (verdão e tabocas) consorciado com rabanete, cultivar Crimsom gigante e o segundo fator pelas doses de jitirana mais esterco bovino $\left(0,0 ; 1,0 ; 2,0 ; 3,0\right.$ e 4,0 kg m- ${ }^{2}$ de canteiro). Utilizou-se a proporção de 1:1, ou seja, uma parte de jitirana para uma parte de esterco bovino. O espaçamento utilizado para o rabanete foi de 0,10 x $0,10 \mathrm{~m}$ com uma planta por cova-1. Já no coentro, o espaçamento utilizado foi de $0,10 \mathrm{x}$ $0,05 \mathrm{~m}$ com cinco plantas cova-1, correspondendo a 1000 plantas $\mathrm{m}^{-2}$ de canteiro. As características avaliadas para os indicadores econômicos foram: renda bruta e renda líquida, taxa de retorno e índice de lucratividade. O melhor desempenho econômico do sistema foi obtido na dose de $4,0 \mathrm{~kg} \mathrm{~m}^{-2}$ de canteiro, com renda bruta de $\mathrm{R} \$ 19.825,00$, renda líquida de $\mathrm{R} \$$ $16.519,00$, taxa de retorno de $\mathrm{R} \$ 6,00$ e índice de lucratividade de $78,7 \%$.
\end{abstract}

Palavras-chaves: Produção orgânica, Indicadores econômicos.

Abstract: Among the vegetables grown in intercropping system in the areas of family production, is the cilantro and radish, short-cycle species (30-35 days to coriander) and (25-30 days for radish). These species are grown in the region of Mossoró / RN in organic production system which uses cattle manure as fertilizer. Thus, an experiment was conducted at the Experimental Farm Rafael Fernandes, Mossoro-RN, in the period from August to October 2014, aiming to assess the economic efficiency of intercropping coriander and radish cultivars fertilized with manure jitirana beef. The work was conducted in a randomized complete block in a factorial $2 \times 5$, with three replications. The first factor consisted of two coriander cultivars (verdão and tabocas) intercropped with radish, cultivate Crimsom giant and the second factor by more jitirana doses of cattle manure $(0.0,1.0,2.0,3.0$ and $4.0 \mathrm{~kg} \mathrm{~m}-2$ site). We used the ratio of 1: 1, or a part of jitirana for a part of manure. The spacing used for the radish was $0.10 \times 0.10 \mathrm{~m}$ with a plant per hill-1. You coriander, the spacing used was $0.10 \times 0.05 \mathrm{~m}$ with five plants pit-1, corresponding to $1000 \mathrm{~m} 2$ plants site. The characteristics evaluated for the economic indicators were gross income and net income, rate of return and profitability index. The better economic performance of the system was obtained at a dose of $4.0 \mathrm{~kg} \mathrm{~m}-2$ site, with gross income of $\mathrm{R} \$ 19,825.00$, net income of R \$ 16,519.00, return fee of $\$ 6.00$ and $78.7 \%$ profitability index.

Keywords: Organic production, Economic indicators.

\footnotetext{
*Autor para correspondência

Recebido para publicação em 03/12/2014; aprovado em 25/12/2014

${ }^{1}$ Mestre em Sistemas Agroindustriais - UFCG/CCTA, Campus Pombal PB -. E-mail: barbara.bmp@hotmail.com

${ }^{2}$ Engenheiro Agrônomo, Doutor em Agronomia- Pesquisador da Universidade Federal Rural do Semi-Árido (UFERSA) E-mail: paulolinhares@ufersa.edu.br; paulojitirana@yahoo.com.br.

${ }^{3}$ Eng. Agrônoma- UFERSA.E-mail:jessyca-duarte@hotmail.com

${ }^{4}$ Mestranda em Sistemas Agroindustriais CCTA-Pombal, UFCG. E-mail:bre.rafa@ hotmail.com

${ }^{5}$ D. Sc. Prof. Associado IV. Curso de Pós graduação em Sistemas Agroindustriais do CCTA/UFCG/Pombal - PB. E-mail: patriciomaracaja@ gmail.com
} 


\section{INTRODUÇÃO}

O consórcio de culturas é um importante componente dos sistemas agrícolas sustentáveis, nos quais se incluem os orgânicos. É uma prática agrícola bastante comum no cultivo de hortaliças em pequenas unidades de produção de regiões tropicais, sobretudo aquelas de base familiar (MONTEZANO; PEIL, 2006). Entre as hortaliças produzidas em sistema consorciado encontra-se o coentro e o rabanete. $\mathrm{O}$ coentro (Coriandrum sativum L.) é uma olerícola de considerável valor e importância em diversas regiões do Brasil, especialmente nas regiões Norte e Nordeste, onde é muito consumido e presente na alimentação diária (FILGUEIRA, 2008). Em relação ao rabanete (Raphanus sativus L.), a planta tem porte reduzido e, nas cultivares de maior aceitação, produz raízes globulares, de coloração escarlate-brilhante e polpa branca (FILGUEIRA, 2008).

Dentro desse sistema de produção, a utilização de adubos de origem animal (estercos) é bastante utilizada, haja vista ser uma prática cultural dos agricultores que labutam na produção orgânica de hortaliças, adubando suas hortas com esse tipo de fertilizante. No entanto, a utilização de forma exclusiva desse insumo encarece a produção dos pequenos agricultores, visto que nem sempre dispõe em suas propriedades esse recurso, tendo que comprar em locais distantes das áreas de produção (LINHARES et al., 2012).

Uma das alternativas para minimizar as limitações do uso do esterco é sua utilização consorciada com adubação verde com leguminosas (MENEZES; SALCEDO 2007). Segundo Silva (1999) o uso de adubos orgânicos de origem vegetal é uma prática útil, econômica e ecologicamente correta para os pequenos e médios produtores de hortaliças. Essa prática vem ganhando cada dia mais espaço entre os agricultores por preservar e/ou restaurar os teores de matéria orgânica e nutriente dos solos.

Os principais efeitos dos adubos orgânicos de origem animal e vegetal sobre as propriedades físico-químicas do solo são: melhoria na adsorção de nutrientes, que é a retenção físico-química de cátions, diminuindo, em consequência, a lixiviação de nutrientes causada pela chuva ou pela irrigação; aumento gradativo da capacidade de troca de cátions (CTC ou T) do solo, melhorando diretamente sua fertilidade (TRANI, 2013).

Segundo Linhares (2013) as espécies mais utilizadas como adubo verde são as leguminosas, pelo fato de produzirem quantidades de fitomassa verde e seca bastante lábil, o que favorece a relação carbono-nitrogênio $(\mathrm{C} / \mathrm{N})$ estreita. Nesse contexto, encontram-se diversas espécies espontâneas da caatinga com potencial para uso como adubo verde, entre elas está: jitirana (Merremia aegyptia L.). Essa espécie apresenta rápido crescimento, tem produção média de fitomassa verde e seca da ordem de 36000 e $4000 \mathrm{~kg}$ ha- 1 respectivamente, com teor de nitrogênio de $26,2 \mathrm{~g} \mathrm{~kg}-1$ na matéria seca (LINHARES et al., 2008), possui relação C/N de 18/1, o que viabiliza a espécie para uso como adubo verde pela sua rápida decomposição da palhada (LINHARES et al., 2012).

Levando-se em consideração a importância social econômica, Brochardt (2004) afirma que para a quantificação dos insumos e serviços componentes de um sistema produtivo, uma planilha de custos é uma ferramenta que permite ao produtor rural investir de modo a obter o maior retorno financeiro e um melhor aproveitamento de insumos e serviços regionais, com menos impacto ecológico, junto com uma correta avaliação dos preços de mercado e do potencial de comercialização, dessa forma permitindo ao produtor gerenciar de forma otimizada o empreendimento. A análise econômica ajuda a interpretar os resultados obtidos nos diferentes sistemas de cultivo e deve ser empregada, tendo como objetivo auxiliar os agricultores na tomada de decisões, sobretudo no que se refere ao que plantar e como plantar.

Objetivou-se então, avaliar a eficiência econômica de cultivares de coentro consorciado com rabanete adubado com jitirana mais esterco bovino.

\section{MATERIAL E MÉTODOS}

O experimento foi realizado na Fazenda Experimental Rafael Fernandes, localizada no distrito de Alagoinha, zona rural de Mossoró-RN, no período de agosto a outubro de 2014, em solo classificado como Latossolo Vermelho Amarelo Argissólico franco arenoso (EMBRAPA, 2006). O distrito de Lagoinha está situado nas seguintes coordenadas: latitude 5o03'37'S e longitude de 37023'50"W Gr, com altitude de aproximada de $72 \mathrm{~m}$, distando $20 \mathrm{~km}$ da cidade de Mossoró-RN. Segundo Thornthwaite, o clima local é DdAa', ou seja, semi-árido (CARMO FILHO et al., 1991).

$\mathrm{O}$ experimento foi conduzido no delineamento de blocos completos casualizados em esquema fatorial $2 \times 5$, com três repetições. O primeiro fator foi constituído de duas cultivares de coentro (verdão e tabocas) consorciado com rabanete, cultivar Crimsom gigante e o segundo fator pelas doses de jitirana mais esterco bovino $(0,0 ; 1,0 ; 2,0 ; 3,0$ e 4,0 kg m-2 de canteiro). Utilizou-se a proporção de $1: 1$, ou seja, uma parte de jitirana para uma parte de esterco bovino. $\mathrm{O}$ espaçamento utilizado para o rabanete foi de $0,10 \times 0,10 \mathrm{~m}$ com uma planta por cova-1. Já no coentro, o espaçamento utilizado foi de 0,10 x 0,05 m com cinco plantas cova-1, correspondendo a 1000 plantas m-2 de canteiro (LINHARES et al., 2014). Sendo essa densidade de plantas, correspondendo à utilizada pelos produtores de coentro na região de Mossoró-RN.

O cultivo consorciado foi estabelecido em fileiras alternadas, correspondendo a uma fileira de rabanete intercalada por uma de coentro no sentido largura dos canteiros. A área total no arranjo foi de $1,44 \mathrm{~m} 2$ e a área útil de $1,0 \mathrm{~m} 2$ contendo 50 plantas de rabanete no espaçamento de $0,10 \times 0,10 \mathrm{~m}$ e 400 plantas de coentro no espaçamento de $0,10 \times 0,05 \mathrm{~m}$, com cinco plantas cova-1 .Para o rabanete plantou-se a cultivar Crimson Gigante e para o coentro, as cultivares plantadas foram (verdão e tabocas), sendo as mais utilizadas pelos agricultores da região Oeste e Alto Oeste do Rio Grande do Norte. O plantio das culturas ocorreu no mesmo dia, haja vista, serem culturas de ciclo curto $(25$ a 30 dias da semeadura até a colheita do rabanete e de 30 a 35 dias da semeadura até a colheita para o coentro). O desbaste ocorreu aos oito dias após a emergência para o rabanete e coentro.

A jitirana foi coletada da vegetação nativa nas proximidades do campus da UFERSA, no início do período da floração, quando a planta apresenta o máximo de concentração de nutrientes. As plantas foram trituradas em máquina forrageira convencional, obtendo-se segmentos entre 
2,0 e 3,0 cm. Estas foram secas ao sol e acondicionado em sacos de ráfia permanecendo com umidade média de $15 \%$, armazenada nas instalações da UFERSA, em ambiente seco adequado para a conservação de material fenado. Por ocasião da instalação do experimento (28/08/2014) foram retiradas cinco amostras de jitirana, encaminhada para o laboratório de fertilidade do solo e nutrição de plantas do Departamento de Ciências Ambientais e Tecnológicas da UFERSA para as análises de carbono $(\mathrm{C})$; nitrogênio $(\mathrm{N})$; fósforo $(\mathrm{P})$; potássio $(\mathrm{K}+)$; cálcio $(\mathrm{Ca} 2+)$; magnésio $(\mathrm{Mg} 2+)$ e relação carbono/nitrogênio. Para a jitirana (Merremia aegyptia) os resultados foram: $570 \mathrm{~g} \mathrm{kg-1} \mathrm{C;} \mathrm{25,0} \mathrm{g} \mathrm{kg-1} \mathrm{N;} 12,5 \mathrm{~g} \mathrm{~kg}-1 \mathrm{P}$; 18,0 g kg-1 K; 12,0 g kg-1 Ca; 16,0 g kg-1 Mg e relação/carbono nitrogênio (23/1). Quantificados em função da matéria seca, levando em consideração os $10 \%$ de umidade, sendo incorporado na camada de $0-20 \mathrm{~cm}$ do solo.

O esterco bovino utilizado foi proveniente da criação de novilhas do setor de bovinocultura da UFERSA, criadas no sistema intensivo, alimentadas com concentrado e tendo como volumoso, o capim canarana (Echinocloa polystochya (Kunth) Hitchc.). Por ocasião da instalação do experimento foram retiradas cinco amostras do montante de esterco utilizado, encaminhadas para o laboratório de fertilidade do solo e nutrição de plantas do Departamento de Ciências Ambientais e Tecnológicas da UFERSA para as análises de $\mathrm{pH}$, nitrogênio $(\mathrm{N})$, matéria orgânica $(\mathrm{MO})$, fósforo $(\mathrm{P})$, potássio $(\mathrm{K}+)$, sódio $(\mathrm{Na}+)$, cálcio $(\mathrm{Ca} 2+)$ e magnésio $(\mathrm{Mg} 2+)$. Apresentou como resultados os seguintes valores: ( pH (água 1:2,5) = 8,06; 19,74 g kg-1 de N; 87,92 g kg-1 de MO; 767,7 mg dm-3 de P; 6827,5 mg dm-3 de K+; 2449,8 mg dm-3 de Na+; 9,85 cmolc dm-3 de Ca2+e 3,09 cmolc dm-3 de $\mathrm{Mg} 2+$ ).

O preparo do solo da área experimental consistiu de uma gradagem seguida de levantamento dos canteiros, utilizando como ferramenta manual a enxada. As irrigações foram efetuadas por microaspersão, com turno de rega diária parcelada em duas aplicações (manhã e tarde). Como tratos culturais, foram realizadas duas capina manual e uma amontoa no rabanete. A incorporação foi realizada quinze dias antes a semeadura. Durante o período de permanência dos resíduos no solo, antecedendo a semeadura, fizeram-se irrigações com a finalidade de manter a umidade do solo a $70 \%$ da capacidade de campo, sendo essa, uma condição ideal para o processo de nitrificarão (NOVAES, 2007).

A colheita do rabanete foi realizada aos 28 dias após a semeadura em 10/10/2014. Já o coentro foi colhido aos 31 dias após a semeadura (13/10/2014).
A validação do uso de jitirana mais esterco bovino no consórcio do coentro com rabanete foi realizada pela determinação da renda bruta, renda líquida, taxa de retorno e índice de lucratividade. Posteriormente, efetuaram-se as conversões por área de $900 \mathrm{~m} 2$.

A renda bruta foi obtida multiplicando-se a produtividade da cultura de cada tratamento pelo valor do produto pago ao produtor, conforme levantamento feito na região de Mossoró-RN no mês de outubro de 2014, que foi de $\mathrm{R} \$ 1,00$ o molho coentro e de $\mathrm{R} \$ 2,00$ para o molho de rabanete, expressa em reais. A renda líquida foi obtida subtraindo-se da renda bruta dos custos de produção. Foram considerados os preços de insumos e serviços vigentes no mês de outubro de 2014, na cidade de Mossoró-RN. A taxa de retorno por real investido foi obtida por meio da relação entre a renda bruta e o custo de produção de cada tratamento. E o índice de lucratividade foi obtido da relação entre a renda líquida e a renda bruta, expresso em porcentagem.

Duas análises de variância univariada foram usadas: uma para avaliar as características agronômicas do coentro no delineamento em blocos casualizados em esquema fatorial $2 \mathrm{x}$ 5 (provenientes de duas cultivares de coentro e cinco doses de jitirana mais esterco bovino) e a outra para as características agronômicas do rabanete em função das cultivares de coentro e doses de jitirana mais esterco bovino, em esquema fatorial 2 $\mathrm{x}$ 5. O aplicativo utilizado foi o ESTAT (KRONKA; BANZATO, 1995). O procedimento de ajustamento de curva de resposta para o fator quantidade (doses de jitirana mais esterco bovino) foi realizado através do Software Table Curve (JANDEL SCIENTIFIC, 1991) e, para o fator qualitativo (cultivares de coentro e cultivares de rabanete) utilizou-se o teste de Tukey ao nível de 5\% de probabilidade para realizar as comparações entre as espécies espontâneas. As funções respostas foram avaliadas com base nos seguintes critérios: lógica biológica, significância do quadrado médio do resíduo da regressão (QMRr), alto valor do coeficiente de determinação (R2), significância dos parâmetros da regressão, utilizando-se o teste t ao nível de $1 \%$ de probabilidade.

\section{RESULTADOS E DISCUSSÃO}

Os indicadores econômicos da eficiência do consorcio de cultivares de coentro consorciado com rabanete sob das doses de jitirana mais esterco bovino incorporado ao solo encontram-se (Tabelas 1, 2 e 3).

Tabela 1. Indicadores econômicos de renda bruta $(\mathrm{RB})$, custo de produção $(\mathrm{CP})$, renda líquida (RL), taxa de retorno (TR) e índice de lucratividade (IL), do consorcio de cultivares de coentro consorciado com rabanete em função de diferentes doses de jitirana mais esterco bovino incorporado ao solo em uma área de $900 \mathrm{~m}^{2}$. CCTA-UFCG-POMBAL-PB, 2014.

\begin{tabular}{lccccc}
\hline FT (Fatores-tratamentos) & $\mathrm{RB}(\mathrm{R} \$)$ & $\mathrm{CP}(\mathrm{R} \$)$ & $\mathrm{RL}(\mathrm{R} \$)$ & $\mathrm{TR}(\mathrm{R} \$)$ & $\mathrm{IL}(\%)$ \\
\hline $0,0 \mathrm{~kg} \mathrm{~J}+$ EST & $7,200,00$ & $3,306,00$ & $3,894,00$ & 2,2 & 54,1 \\
$1,0 \mathrm{~kg}$ J + EST & $12,600,00$ & $3,306,00$ & $9,294,00$ & 3,8 & 73,8 \\
$2,0 \mathrm{~kg} \mathrm{~J}+$ EST & $16,200,00$ & $3,306,00$ & $12,894,00$ & 4,9 & 79,6 \\
$3,0 \mathrm{~kg}$ J + EST & $18,900,00$ & $3,306,00$ & $15,594,00$ & 5,7 & 82,5 \\
$4,0 \mathrm{~kg} \mathrm{~J}+$ EST & $19,800,00$ & $3,306,00$ & $16,494,00$ & 6,0 & 83,3 \\
\hline
\end{tabular}

FT (Fatores-tratamentos); PD (Produção de coentro em kg m ${ }^{-2}$ de canteiro); PP (Preço pago pelo consumidor por molho de coentro e de rabanete); RB (Renda bruta, que consiste na multiplicação do preço pago pelo consumidor vezes a produção); CP (Custo de produção por canteiro de $900 \mathrm{~m}^{2}$ ); $\mathbf{R L}$ (Renda liquida que consiste em subtrair a renda bruta do custo de produção); TR (Taxa de retorno, indica o que o produtor terá para cada real investido, foi obtida por meio da relação entre a renda bruta e o custo total de cada tratamento) e IL (Índice de lucratividade indica em termos percentuais o retorno do investimento, foi obtido pela relação entre a renda líquida e a renda bruta, multiplicado por 100 e expresso em porcentagem). 
Tabela 2. Indicadores econômicos de renda bruta $(\mathrm{RB})$, custo de produção $(\mathrm{CP})$, renda líquida (RL), taxa de retorno (TR) e índice de lucratividade (IL), para cultivares de coentro consorciado com rabanete em função de diferentes doses de jitirana mais esterco bovino incorporado ao solo no número de molhos de rabanete e coentro $\mathrm{m}^{-2}$ de canteiro (A1) e por área de $900 \mathrm{~m}^{2}$ (A2). CCTA-UFCG-POMBAL-PB, 2014.

\begin{tabular}{|c|c|c|c|c|c|c|c|c|}
\hline $\begin{array}{l}\text { FT (Fatores- } \\
\text { tratamentos) }\end{array}$ & A1 & A2 & $\begin{array}{l}\text { PP } \\
(\mathrm{R} \$) \\
\end{array}$ & $\begin{array}{c}\mathrm{RB} \\
(\mathrm{R} \$) \\
\end{array}$ & $\begin{array}{c}\mathrm{CP} \\
(\mathrm{R} \$) \\
\end{array}$ & $\begin{array}{c}\mathrm{RL} \\
(\mathrm{R} \$) \\
\end{array}$ & $\begin{array}{c}\mathrm{TR} \\
(\mathrm{R} \$) \\
\end{array}$ & IL $(\%)$ \\
\hline \multicolumn{9}{|c|}{ RABANETE CONSORCIADO COM COENTRO } \\
\hline $0,0 \mathrm{~kg} \mathrm{~J}+\mathrm{EST}$ & 2 & 1800 & 2,00 & $3,600,00$ & $3,306,00$ & 294,00 & 1,08 & 8,16 \\
\hline $1,0 \mathrm{~kg} \mathrm{~J}+\mathrm{EST}$ & 4 & 3600 & 2,00 & $7,200,00$ & $3,306,00$ & $3,894,00$ & 2,17 & 54,08 \\
\hline $2,0 \mathrm{~kg} \mathrm{~J}+\mathrm{EST}$ & 5 & 4500 & 2,00 & $9,000,00$ & $3,306,00$ & $5,694,00$ & 2,72 & 63,26 \\
\hline $3,0 \mathrm{~kg} \mathrm{~J}+\mathrm{EST}$ & 6 & 5400 & 2,00 & $10,800,00$ & $3,306,00$ & $7,494,00$ & 3,26 & 69,38 \\
\hline $4,0 \mathrm{~kg} \mathrm{~J}+\mathrm{EST}$ & 6 & 5400 & 2,00 & $10,800,00$ & $3,306,00$ & $7,494,00$ & 3,26 & 69,38 \\
\hline \multicolumn{9}{|c|}{ COENTRO CONSORCIADO COM RABANETE } \\
\hline $0,0 \mathrm{~kg} \mathrm{~J}+\mathrm{EST}$ & 4 & 3600 & 1,00 & $3,600,00$ & $3,306,00$ & 294,00 & 1,08 & 8,2 \\
\hline $1,0 \mathrm{~kg} \mathrm{~J}+\mathrm{EST}$ & 6 & 5400 & 1,00 & $5,400,00$ & $3,306,00$ & $2,094,00$ & 1,63 & 38,8 \\
\hline $2,0 \mathrm{~kg} \mathrm{~J}+\mathrm{EST}$ & 8 & 7200 & 1,00 & $7,200,00$ & $3,306,00$ & $3,894,00$ & 2,17 & 54,1 \\
\hline $3,0 \mathrm{~kg} \mathrm{~J}+\mathrm{EST}$ & 9 & 8100 & 1,00 & $8,100,00$ & $3,306,00$ & $4,794,00$ & 2,45 & 59,2 \\
\hline $4,0 \mathrm{~kg} \mathrm{~J}+\mathrm{EST}$ & 10 & 9000 & 1,00 & $9,000,00$ & $3,306,00$ & $5,694,00$ & 2,72 & 63,3 \\
\hline
\end{tabular}

FT (Fatores-tratamentos); PD (Produção de coentro em kg m ${ }^{-2}$ de canteiro); PP (Preço pago pelo consumidor por molho de coentro e de rabanete); RB (Renda bruta, que consiste na multiplicação do preço pago pelo consumidor vezes a produção); $\mathbf{C P}$ (Custo de produção por canteiro de 900 m²); $\mathbf{R L}$ (Renda liquida que consiste em subtrair a renda bruta do custo de produção); TR (Taxa de retorno, indica o que o produtor terá para cada real investido, foi obtida por meio da relação entre a renda bruta e o custo total de cada tratamento) e IL (Índice de lucratividade indica em termos percentuais o retorno do investimento, foi obtido pela relação entre a renda líquida e a renda bruta, multiplicado por 100 e expresso em porcentagem).

Tabela 3. Coeficientes de custos de produção de uma área de $900 \mathrm{~m}^{2}$, cultivado com cultivares de coentro consorciado com rabanete adubado com diferentes doses de jitirana mais esterco bovino. CCTA-UFCG- POMBAL. 2014.

\begin{tabular}{|c|c|c|c|c|}
\hline DISCRIMINAÇÃO & UND & QT & $\mathbf{P R}(\mathbf{R} \$)$ & Total $(\mathbf{R} \$)$ \\
\hline \multicolumn{5}{|l|}{ I - Insumos } \\
\hline Semente: rabanete (Crimsom gigante) & $\mathrm{Kg}$ & 05 & 90,00 & 450,00 \\
\hline Semente: coentro (Verdão e Tabocas) & $\mathrm{Kg}$ & 04 & 14,00 & 56,00 \\
\hline Esterco bovino na dose de $2,0 \mathrm{~kg} \mathrm{~m}^{-2}$ de canteiro & $\mathrm{Kg}$ & 1800 & 0,20 & 360,00 \\
\hline Sub-Total I & & & & 866,00 \\
\hline Corte da jitirana na dose $2,0 \mathrm{~kg} \mathrm{~m}^{-2}$ de canteiro & $\mathrm{d} / \mathrm{h}$ & 05 & 40,00 & 200,00 \\
\hline Trituração manual das espécies & $\mathrm{d} / \mathrm{h}$ & 03 & 40,00 & 120,00 \\
\hline Secagem & $\mathrm{d} / \mathrm{h}$ & 03 & 40,00 & 120,00 \\
\hline Limpeza da área & $\mathrm{d} / \mathrm{h}$ & 02 & 40,00 & 80,00 \\
\hline Confecção de canteiros & $\mathrm{d} / \mathrm{h}$ & 03 & 40,00 & 120,00 \\
\hline Distribuição e incorporação da jitirana mais esterco bovino & $\mathrm{d} / \mathrm{h}$ & 04 & 40,00 & 160,00 \\
\hline Plantio do rabanete e coentro & $\mathrm{d} / \mathrm{h}$ & 02 & 40,00 & 80,00 \\
\hline Desbaste & $\mathrm{d} / \mathrm{h}$ & 04 & 40,00 & 160,00 \\
\hline Capina manual & $\mathrm{d} / \mathrm{h}$ & 03 & 40,00 & 120,00 \\
\hline Bombeamento da água de irrigação & $\mathrm{Kw} / \mathrm{h}$ & & & 40,00 \\
\hline Bomba de irrigação $3 / 4$ & und & 01 & 200,00 & 200,00 \\
\hline Microaspessores & und & 100 & 2,00 & 200,00 \\
\hline Mangueira de irrigação (100 m) & rolo & 07 & 40,00 & 280,00 \\
\hline Colheita do coentro e do rabanete & $\mathrm{d} / \mathrm{h}$ & 07 & 40,00 & 280,00 \\
\hline Comercialização do coentro e do rabanete & $\mathrm{d} / \mathrm{h}$ & 07 & 40,00 & 280,00 \\
\hline Total (II) & & & & $2,440,00$ \\
\hline Total (I + II) & & & & $3,306,00$ \\
\hline
\end{tabular}

Foi verificado aumento da renda bruta á medida em que foram adicionadas as diferentes doses de jitirana mais esterco bovino, sendo que a renda máxima foi de $\mathrm{R} \$$ 19,825,00 com a dose de 4,0 m-2 de canteiro de jitirana mais esterco bovino (Figura 1). Esse valor obtido esta dentro do padrão de produção orgânica, sendo de grande importância para os agricultores que labutam na produção orgânica de hortaliças.

A renda liquida teve comportamento semelhante, onde o melhor rendimento foi obtido na dose de $4,0 \mathrm{~kg} \mathrm{~m}$ de canteiro de jitirana mais esterco bovino, com valor médio de $\mathrm{R} \$ 16,519,00$ e taxa de retorno de $\mathrm{R} \$ 6,0$ e índice de lucratividade de $78,7 \%$ (Figura $2 ; 3$ e 4). A lucratividade representa, em percentual, o rendimento real obtido com a comercialização de certo produto, ou seja, é quanto o produtor tem de renda, após serem descontados os custos de produção. O objetivo principal da produção agrícola é maximizar lucros, com minimização de custos, então, ao planejar a produção agrícola não se deve pensar apenas em otimizar a produção em determinada condição de cultivo, mas também na alocação adequada de recursos disponíveis que viabilizem a implantação de uma determinada cultura. 
Figura 1. Renda bruta do consorcio de rabanete com coentro sob diferentes doses de jitirana mais esterco bovino incorporada ao solo. CCTA-UFCG- POMBAL-PB, 2014.

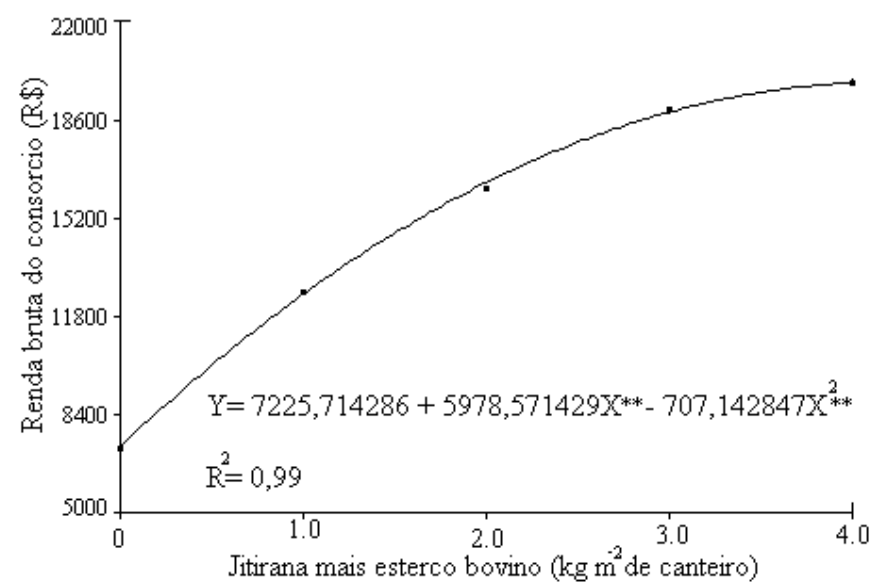

Figura 2. Renda líquida do consorcio de rabanete com coentro sob diferentes doses de jitirana mais esterco bovino incorporada ao solo. CCTA-UFCG- POMBAL-PB, 2014.

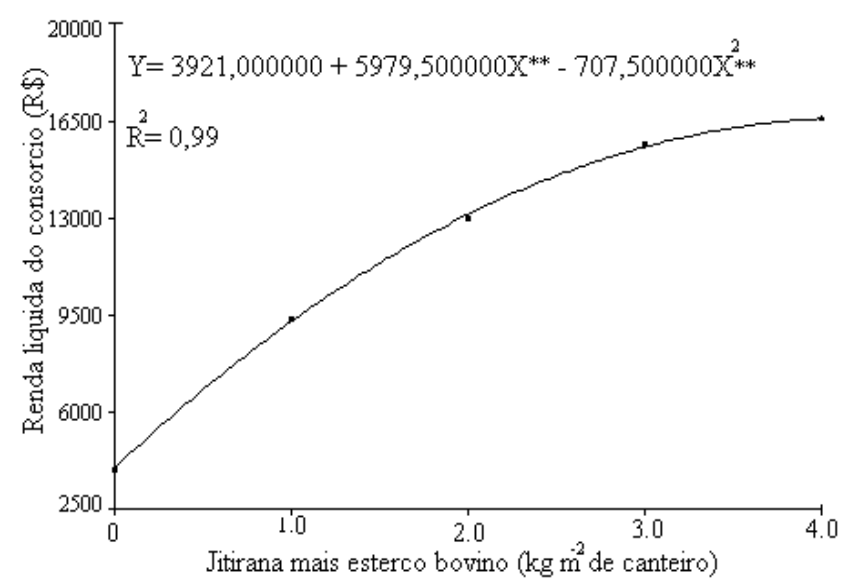

Figura 3. Taxa de retorno do consorcio de rabanete com coentro sob diferentes doses de jitirana mais esterco bovino incorporada ao solo. CCTA-UFCG- POMBAL-PB, 2014.

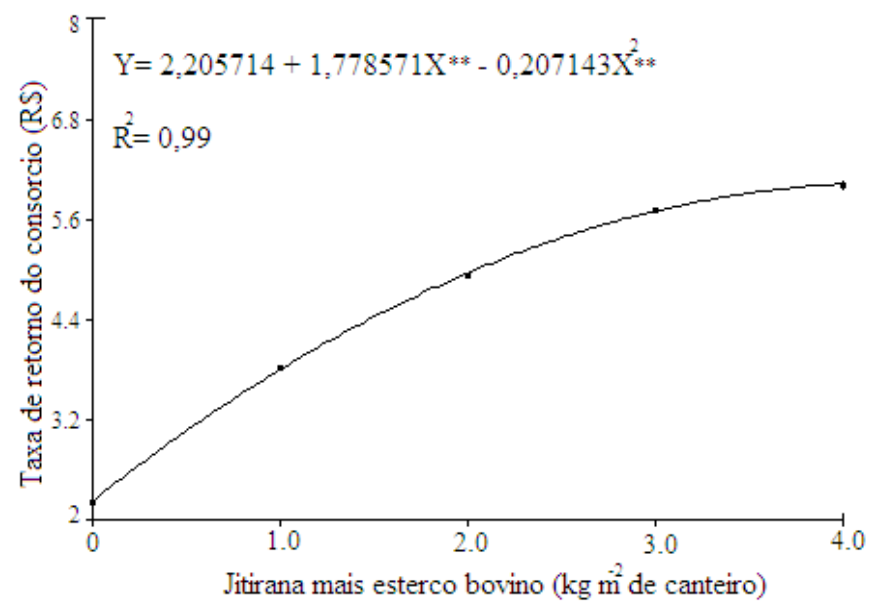

Figura 4. Índice de lucratividade do consorcio de rabanete com coentro sob diferentes doses de jitirana mais esterco bovino incorporada ao solo. CCTA-UFCG- POMBAL-PB, 2014.

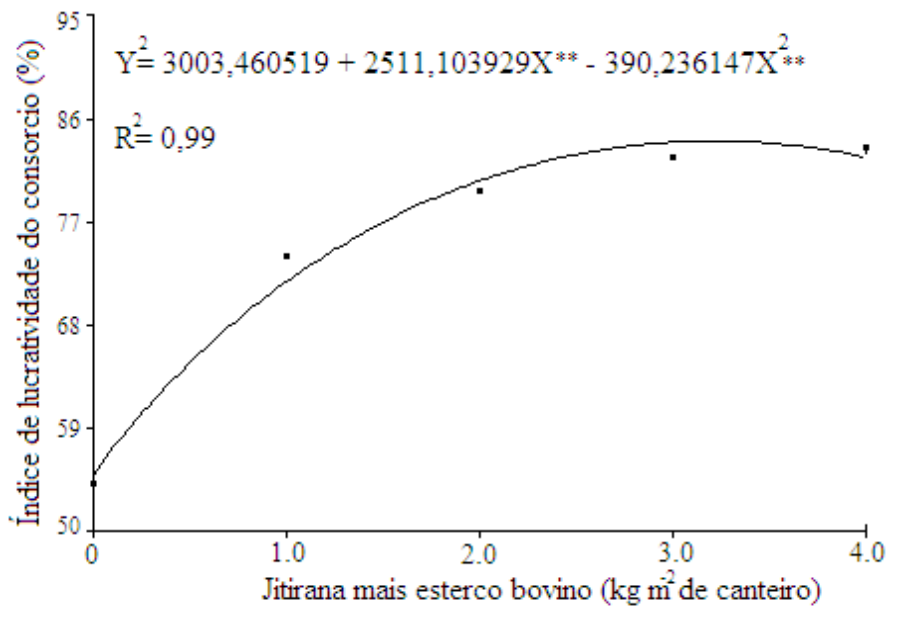

\section{CONCLUSÕES}

Não se observou interação entre os fatores estudados. O melhor desempenho agroeconômico do sistema foi obtido na dose de 4,0 kg m-2 de canteiro, com renda bruta de $\mathrm{R} \$$ $19.825,00$, renda líquida de $\mathrm{R} \$ 16.519,00$, taxa de retorno de $\mathrm{R} \$ 6,00$ e índice de lucratividade de 78,7\%.

\section{REFERÊNCIAS BIBLIOGRÁFICAS}

BROCHARDT, I. Desenvolvimento de metodologia para elaboração de custos de produção das principais culturas exploradas em Santa Catarina. Florianópolis: Instituto CEPA, 2004. 67 p.

CARMO FILHO, F. do; ESPÍNOLA SOBRINHO, J.; MAIA NETO, J.M. Dados climatológicos de Mossoró: um município semi-árido nordestino. Mossoró: ESAM, 1991, 121p. (Coleção mossoroense, série C, 30).

\section{EMPRESA BRASILEIRA DE PESQUISA} AGROPECUÁRIA - EMBRAPA. Sistema brasileiro de classificação de solos. 2.ed. Rio de Janeiro: Embrapa, 2006. 306p.

FILGUEIRA, F.A.R. Novo Manual de Olericultura: Agrotecnologia moderna na produção e comercialização de hortaliças. Viçosa: UFV. 2008. 402 p.

JANDEL SCIENTIFIC. Table curve: curve fitting software. Corte Madera, CA: Jandel Scientific, 1991. 280p.

KRONKA, S.N.; BANZATO, D.A. Estat: sistema para análise estatística versão 2. 3. ed. Jaboticabal: Funep, 1995. $243 \mathrm{p}$.

LINHARES, P. C. F. Adubação verde como condicionadora do solo. Revista Campo e negócios, Minas Gerais, v.11, n.127, p.22-23, 2013. 
LINHARES, P. C. F.; LEITE DE LIMA, G. K.; MADALENA. J. A. da S.; MARACAJÁ, P. B.; FERNANDES, P. L. de O. Adição de jitirana ao solo no desempenho de rúcula cv. Folha Larga. Revista Caatinga, Mossoró, v.21, n.5, p.89-94, 2008.

LINHARES, P. C. F.; OLIVEIRA, J. D. de.; PEREIRA, M. F. S.; FERNANDES, J. P. P.; DANTAS, R. P. Espaçamento para a cultura do coentro adubado com palha de carnaúba nas condições de Mossoró-RN. Revista verde, Pombal, v.9, n.3, p.01 - 06, 2014.

LINHARES, P. C. F.; PEREIRA, M. F. S.; ASSIS, J. P. de A.; BEZERRA, A. K. de H. Quantidades e tempos de decomposição da jitirana no desempenho agronômico do coentro. Ciência Rural, Santa Maria, v.42, n.2, p.243248, 2012.

MENEZES, R.S.C.; SALCEDO. I.H. Mineralização de N após incorporação de adubos orgânicos em um Neossolo
Regolítico cultivado com milho. Revista Brasileira de Engenharia Agrícola e Ambiental, v.11, p.361-367, 2007.

MONTEZANO E.M; PEIL R.M.N. 2006. Sistema de consórcio na produção de hortaliças. Revista Brasileira de Agrociência, Pelotas, v.12, n.2, p.129 -132, 2006. n.3, p.703-706, 2005.

NOVAIS, R.F. Fertilidade do solo. In: MEURER, E.J. Fatores que influenciam o crescimento e o desenvolvimento das plantas. Viçosa: SBCS, p. 65-90, 2007.

SILVA, F. C. da. Manual de análises químicas de solos, plantas e fertilizantes. Brasília: Embrapa Comunicação para a Transferência de Tecnologia, 1999. 370p.

TRANI et al. Adubação Orgânica de Hortaliças e Frutíferas. Campinas (SP) fevereiro de 2013. 